Products and Services In Practice is provided to readers using text and images from the manufacturer, supplier or distributor and does not imply endorsement by $B D J$ In Practice. Normal and prudent research should be exercised before purchase or use of any product mentioned.

Please send product and services news through to David Westgarth, $B D J$ In Practice via: David.Westgarth@bda.org

\section{Expand your Enhanced CPD horizons}

Johnson \& Johnson Ltd., the makers of LISTERINE, are delighted to announce the expansion of their Enhanced CPD educational programme.

Re-launched for 2021, the programme will be added to each month with Enhanced CPD content at no cost to you, to support you in improving and maintaining the oral health of your patients.

New articles include:

$\rightarrow$ Evaluating oral care for hard-to-reach areas

This article considers the challenges all patients face when brushing and cleaning interdentally, as well exploring the limitations resulting from reduced dexterity, offering evidence-based solutions to help support their oral health.

Development outcomes: A, C, D

\section{$\rightarrow$ Oral health and mental health}

This article explores the measures dental professionals may need to incorporate into their care, to ensure any special needs are met when dealing with patients with possible mental health issues.

Development outcomes: A, B, C, D

$\rightarrow$ Oral health, pregnancy and the first year

This article explores the oral health needs of pregnant women and how to raise patient awareness in that regard, as well as looking at the first year following the birth for both mother and child.

Development outcomes: A, C, D

The resources to help support your continuing professional development are available at www.listerineprofessional. co.uk/cpd-educational-programme.

\title{
Vital ventilation protects patients and reduces 'fallow time' for dentists' surgeries
}

For dentists looking for ventilation advice Vent-Axia is committed to improving indoor air quality and public health and has helped in the national response against COVID-19. The company can advise on a wide range of ventilation solutions that are ideal for dental surgeries depending on practice. Where dentists are keen to add extra airflow easily and quickly rather than upgrading a whole building system, consultants can consider adding commercial extraction fans to increase fresh air.

Some dental practices may think upgrading ventilation is a big investment since installing a whole building ventilation system can cost in the region of $£ 10 \mathrm{k}$, making it prohibitive for some practices - but there are more affordable options on offer by opting for unitary ventilation. Extract/supply fans can simply be installed through a window or wall offering little disruption. For example, a traditional Vent-Axia T-Series window fan is available from as little as $£ 325.17$. The only other cost is the installation of the fan through a window - so for a relatively small investment, dentists can benefit from the ventilation result they need to reduce fallow time and so see more patients.

Vent-Axia’s T-Series commercial fan offers high performance ventilation with low running costs. With both window and wall options available, as well as Lo-Carbon models, it is both durable and reliable. Available with four sizes of extract/intake fans and an easy fit connector Top Socket allowing fast and trouble-free mains connection, the T-Series is easy to install and replace. Alternatively, for ducted applications energy efficient ACM Mixed Flow In-Line fans offer quiet ventilation with two and half times the pressure of conventional axial fans. Their compact design also makes them ideal for many ducted applications and they can operate in both horizontal and vertical positions.

For dentists wishing to upgrade ventilation in the whole building there are heat recovery or demand ventilation options. The Integra Heat recovery unit is ideal for smaller commercial applications up to $180 \mathrm{~m}^{2}$. With low power consumption and heat recovery, the unit extracts heat energy from the outgoing air and transfers this energy to the incoming fresh air tempering it, without the two air streams mixing. Meanwhile, D-ERV systems have sophisticated controls and sensors that can be used to easily adapt the system to the new COVID-19 requirements, providing ventilation appropriate to occupant needs. Vent-Axia's Sentinel Totus ${ }^{2}$ D-ERV demand ventilation features low energy EC/DC motors, up to $90 \%$ energy recovery and G4 replaceable synthetic filters, complete with filter change warning, and optional high grade F6 filters.

Vent-Axia has created a dedicated web page at www.vent-axia.com/ventilationin-dental-practices to inform and advise dental surgeries on the vital role of ventilation. For further information on all products and services offered by Vent-Axia call 03448560590 or visit www.vent-axia. com.

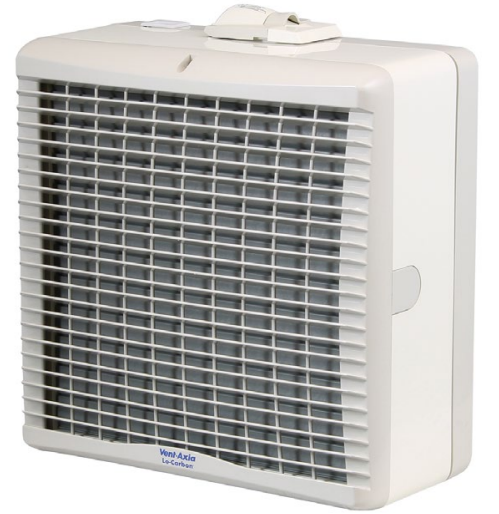

